\title{
Identification of candidate genes that may contribute to the metastasis of prostate cancer by bioinformatics analysis
}

\author{
LINGYUN LIU, KAIMIN GUO, ZUOWEN LIANG, FUBIAO LI and HONGLIANG WANG \\ Department of Andrology, The First Hospital of Jilin University, Changchun, Jilin 130021, P.R. China
}

Received August 8, 2016; Accepted September 13, 2017

DOI: $10.3892 / 01.2017 .7404$

\begin{abstract}
To screen for marker genes associated with to the metastasis of prostate cancer (PCa), in silico analysis of the Gene Expression Omnibus dataset GSE27616, which included 4 metastatic and 5 localized PCa tissue samples, was performed. Differentially expressed genes (DEGs) were identified. Their potential functions were identified by Gene Ontology and Kyoto Encyclopedia of Gene Genomes pathway enrichment analyses. Furthermore, protein-protein interaction (PPI) networks for DEGs were constructed using Cytoscape. Module analysis of the PPI networks was performed with Cluster ONE. A total of 561 DEGs were screened, including 208 upregulated and 353 downregulated genes. Proliferating cell nuclear antigen $(P C N A)$ and cluster of differentiation $4(C D 4)$ exhibited the highest degrees of connectivity in the PPI networks for up- and down-regulated DEGs, respectively. The DEGs in module A, including CD58, 2, 4 and major histocompatibility complex, class II DP- $\beta 1$ were enriched in 'cell adhesion molecules'. Anaphase promoting complex subunit 4, cell division cycle 20 and cell division cycle 16 in module $\mathrm{B}$ were primarily enriched in 'cell cycle'. The DEGs, including $C D 4, P C N A$ and baculoviral IAP repeat containing 5, may have critical roles in PCa metastasis and could thus be used as novel biomarker candidates for metastatic PCa. However, further studies are required to verify these results.
\end{abstract}

Correspondence to: Dr Hongliang Wang, Department of Andrology, The First Hospital of Jilin University, 71 Xinmin Street, Changchun, Jilin 130021, P.R. China

E-mail: hongliangwang_0908@hotmail.com

Abbreviations: CAMs, cell adhesion molecules; DAVID, database for annotation visualization and integrated discovery; DEGs, differentially expressed genes; FDR, false discovery rate; GEO, gene expression omnibus; GO, Gene Ontology; HIF, hypoxia inducible factor; HPRD, Human Protein Reference Database; KEGG, Kyoto Encyclopedia of Genes and Genomes; PPI, protein-protein interaction; $\mathrm{PCa}$, prostate cancer; PSA, prostate specific antigen; TRP, transient receptor potential

Key words: prostate cancer, metastasis, differentially expressed genes, protein-protein interaction, module

\section{Introduction}

Prostate cancer ( $\mathrm{PCa})$ is the most common malignancy among men worldwide (1) as well as the second leading cause of cancer-associated mortality $(2,3)$. According to a previous study, PCa resulted in $\sim 256,000$ incidences of mortality in 2010 globally (4). This type of cancer is caused by a combination of and environmental factors, including age, ethnicity and diet, and genetic causes (5). Although PCa is curable in the early stages by radiation therapy or surgical resection, the majority of patients with locally advanced or metastatic PCa lack a curative treatment option (6).

Metastasis, the most common cause of cancer-associated mortality, represents the final and the most devastating stage of tumor progression (7). The majority of cancer types originate from epithelial tissues and, upon metastasis, leave the primary tumor and invade the adjacent tissue (8). $\mathrm{PCa}$ cells may thus spread from the prostate to other regions of the body. Pelvic lymph node involvement is the first indication of metastasis in the majority of cases of $\mathrm{PCa}$, followed by transfers to other organs, including bones, lungs and liver (9). The metastasis of PCa to regional lymph nodes is a frequent early event that is associated with poor clinical treatment (10). Aurora kinase A is overexpressed in metastatic PCa and is associated with tumor development and progression (11). In addition, the expression of extracellular signal-regulated kinase, p38 mitogen-activated protein kinase and c-Jun-N-terminal kinase were demonstrated to be significantly reduced in metastatic PCa tissue compared with primary $\mathrm{PCa}$ (12). At present, prostate specific antigen (PSA), encoded by the prostate-specific gene kallikrein-3 (KLK3), is a serum biomarker used for the detection of PCa (13). However, the prognostic value of PSA is limited due to the variation in its specificity and sensitivity (14). Therefore, it is urgent to screen for valid biomarkers for metastatic PCa.

The present study investigated the global gene expression profile of localized and metastatic PCa, and identified the differentially expressed genes (DEGs) between localized and metastatic PCa tissue samples. Protein-protein interaction (PPI) networks were constructed for the DEGs, and pathway analyses of the PPI networks were performed. Finally, a set of genes associated with PCa metastasis was identified. The present study aimed to identify key genes that were involved in the metastasis of $\mathrm{PCa}$ and provide clues for the treatment of $\mathrm{PCa}$, by bioinformatics methods. 


\section{Materials and methods}

Affymetrix microarray data. Gene expression profiles (identification no., GSE27616) from the study of Kim et al (15), which were deposited in the National Center for Biotechnology Information Gene Expression Omnibus (GEO) database (https://www.ncbi.nlm.nih.gov/geo/) were extracted, including 4 metastatic and 5 localized PCa tissue sample expression profiles. Raw data had been collected using the Agilent-014850 Whole Human Genome Microarray 4x44K G4112F array platform (Agilent Technologies, Inc., Santa Clara, CA, USA).

DEGs analysis. The original expression data from all conditions was scaled using the robust multi-array average (RMA) method (16), with the default settings in Bioconductor (http://bioconductor.org/help/search/index .html?q=AgiMicroRna) (17) and a linear model was constructed. Linear Models for Microarray Data package (18) was applied to identify DEGs. To reduce the likelihood of false positive results, the Benjamini-Hochberg method (19) was used to adjust the raw P-value. Finally, DEGs with the cut-off criteria $\left[\log _{2}\right.$ Fold change $\left.(\mathrm{FC})\right]>1$ and $\mathrm{P}<0.05$ were selected.

Gene ontology (GO) and pathway enrichment analysis. The Database for Annotation, Visualization and Integrated Discovery (DAVID; version 6.7, http://david.abcc.ncifcrf.gov/) is an annotation tool that allows for the extraction of biological meaning from a large list of genes (20). In the present study, DAVID was used to identify over-represented GO terms in the biological process category based on the hypergeometric distribution with a false discovery rate (FDR) $<0.05$ and gene count $>2$. Kyoto Encyclopedia of Genes and Genomes (KEGG) pathway enrichment analysis was applied to identify the main functional and metabolic pathways enriched in DEGs from PCa metastasis. $\mathrm{P}<0.05$ was selected as the cut-off criterion.

PPI network construction. To demonstrate potential PPIs, PPI data from the Human Protein Reference Database (HPRD) (21) and the Biological General Repository for Interaction Database (BioGRID) (22) were used to identify interactions among the DEGs. On the basis of this dataset, PPI networks of the DEGs were constructed in the Search Tool for the Retrieval of Interacting Gene database (23) using Cytoscape (version 3.2.0; http://www.cytoscape.org/release_notes_3_2_0.html) software (24).

Screening and analyses of relevant regulatory network modules. The functional modules of the network for downregulated DEGs were investigated with Cluster ONE in Cytoscape (25). The sub-modules were screened with a criterion of $\mathrm{P}<0.01$. Finally, the two most significant sub-modules from the modularity analysis were selected for GO functional enrichment analysis and KEGG pathway enrichment analysis.

\section{Results}

DEGs between metastatic and localized PCa cells. To identify DEGs between metastatic and localized PCa samples, the publicly available microarray dataset GSE27616 was obtained from the GEO database. DEGs with a $\left(\log _{2} \mathrm{FC}\right)>1$ and $\mathrm{P}<0.05$ were identified. A total of 561 DEGs were obtained, including 208 upregulated genes and 353 downregulated genes.

KEGG pathway enrichment and GO analysis of DEGs. KEGG pathway enrichment analyses were performed for upregulated and downregulated DEGs. The results revealed that the upregulated DEGs were enriched in 'renal cell carcinoma' ( $\mathrm{P}=0.00848)$, 'cell cycle' $(\mathrm{P}=0.01438)$ and 'homologous recombination' ( $\mathrm{P}=0.04125$; Table I). The downregulated DEGs were enriched in 'vascular smooth muscle contraction' $(\mathrm{P}=0.00889)$, 'calcium signaling pathway' $(\mathrm{P}=0.03116)$ and 'dilated cardiomyopathy' ( $\mathrm{P}=0.0436$; Table II).

To investigate whether DEGs share specific functional features, the online biological classification software DAVID was used to identify overrepresented GO categories in biological process. Gene count $>2$ and $\mathrm{P}<0.05$ were selected as threshold values. There were 48 categories enriched in upregulated DEGs and 94 categories enriched in downregulated DEGs that met these criteria. The most frequent GO functions of upregulated DEGs included 'response to hypoxia' $\left(\mathrm{P}=2.72 \times 10^{-8}\right)$, 'response to oxygen levels' $\left(\mathrm{P}=4.81 \times 10^{-8}\right)$ and 'cell cycle phase' ( $\mathrm{P}=6.60 \times 10^{-4}$; Table III). The GO functions of downregulated DEGs included 'response to organic substance' $\left(\mathrm{P}=3.50 \times 10^{-5}\right)$, 'response to cytokine stimulus' $\left(\mathrm{P}=2.70 \times 10^{-4}\right)$ and 'response to hypoxia' ( $\mathrm{P}=3.07 \times 10^{-4}$; Table IV).

Construction of an integrated PPI network. PPI interaction data were obtained from HPRD and BioGRID, and PPI networks were constructed for upregulated and downregulated DEGs (Figs. 1 and 2). In the PPI network for upregulated DEGs, the top ten nodes with the highest connectivity were proliferating cell nuclear antigen (PCNA), cell division cycle associated 8 (CDCA8), cell division cycle 20 (CDC20), baculoviral IAP repeat containing 5 (BIRC5), DNA polymerase $\delta$-1, chromatin licensing and DNA replication factor 1 , kinesin family member $2 \mathrm{C}$, checkpoint kinase 1 , aurora kinase $\mathrm{B}$ $(A U R K B)$ and thymidine kinase 1 . In the PPI network for downregulated DEGs, the top ten nodes with the highest connectivity were $C D 4, C C R 5, L C K, \mathrm{C}-\mathrm{X}-\mathrm{C}$ motif chemokine ligand 12 (CXCL12), fibromodulin, fibroblast growth factor 2, CXCL9, CD2, CD69 and CCL5. The connectivity degree of these proteins was $>10$ (Table V).

Analysis of modules. Module A $\left(\mathrm{P}=3.029 \times 10^{-5}\right)$ and module $\mathrm{B}\left(\mathrm{P}=2.901 \times 10^{-4}\right.$; Fig. 3) were isolated from the PPI network of the downregulated DEGs using Cluster ONE software. GO and KEGG pathway analysis were then performed to analyze the modules.

In module $\mathrm{A}$, genes including CCL2, CCR5, CXCL9, CXCL11 and CCL5 were enriched in 'chemokine signaling pathway' $\left(\mathrm{P}=4.77 \times 10^{-4}\right)$ and 'cytokine-cytokine receptor interaction' ( $\mathrm{P}=0.00171)$; genes including $C D 58, C D 2, C D 4$ and major histocompatibility complex, class II, DP- $\beta 1$ (HLA-DPBI) were enriched in 'adhesion molecules' $(\mathrm{P}=0.00242)$; genes including $C D 38,2$ and 4 were enriched in 'hematopoietic cell lineage' ( $\mathrm{P}=0.01408)$; genes including CXCL9, CXCL11 and CCL5 were enriched in 'toll-like receptor signaling pathway' $(\mathrm{P}=0.01912)$.

In module $\mathrm{B}$, genes including anaphase promoting complex subunit 4 (ANAPC4), protein phosphatase 3 catalytic 
Table I. Enriched Kyoto Encyclopedia of Genes and Genomes pathways for the upregulated differentially expressed genes.

\begin{tabular}{lccl}
\hline Term & Count & P-value & Genes \\
\hline hsa05211: Renal cell carcinoma & 5 & 0.00848 & BRAF, CREBBP, EGLN3,EGLN1, FLCN \\
hsa04110: Cell cycle & 6 & 0.01438 & CDKN2D,CREBBP,PKMYT1,CHEK1,CDC20, PTTG1 \\
hsa03440: Homologous recombination & 3 & 0.04125 & POLD1, RAD52, RAD54L \\
\hline
\end{tabular}

Table II. Enriched Kyoto Encyclopedia of Genes and Genomes pathways for the downregulated differentially expressed genes.

\begin{tabular}{lccc}
\hline Term & Count & P-value & \multicolumn{1}{c}{ Genes } \\
\hline hsa04270: Vascular smooth muscle contraction & 8 & 0.00889 & $\begin{array}{l}\text { KCNMA1, ACTG2, PLA2G4A, PLCB4, ACTA2, } \\
P P P 1 R 12 B, M Y L K, I T P R 2\end{array}$ \\
hsa04020: Calcium signaling pathway & 9 & 0.03116 & $\begin{array}{l}C D 38, S L C 8 A 1, P L C B 4, P H K B, P L N, G R P R, \\
P P P 3 C B, M Y L K, I T P R 2\end{array}$ \\
hsa05414: Dilated cardiomyopathy & & & SLC8A1,DES, PLN,DMD,TPM2, CACNA2D2 \\
\hline
\end{tabular}

Table III. Top ten enriched GO functions of upregulated differentially expressed genes.

\begin{tabular}{|c|c|c|c|}
\hline GO term & Count & P-value & Genes \\
\hline 0001666: Response to hypoxia & 13 & $2.72 \times 10^{-8}$ & $\begin{array}{l}\text { ALDOC, CREBBP, EGLN3, EGLN1, UBE2B, ADA, DDIT4, } \\
\text { ADM, PLOD2, SERPINA1, SCNN1B, ANGPTL4, MT3 }\end{array}$ \\
\hline 0070482: Response to oxygen levels & 13 & $4.81 \times 10^{-8}$ & $\begin{array}{l}\text { ALDOC, CREBBP , EGLN3, EGLN1, UBE2B, ADA, DDIT4, } \\
\text { ADM, PLOD2, SERPINA1, SCNN1B, ANGPTL4, MT3 }\end{array}$ \\
\hline 0022403: Cell cycle phase & 14 & $6.60 \times 10^{-4}$ & $\begin{array}{l}\text { PKMYT1, CDC20, CHEK1, PTTG1, RCC1, RAD52, } \\
\text { RAD54L, KIF2C, CDCA8, CDKN2D, POLD1, STMN1, CIT, } \\
\text { FANCA }\end{array}$ \\
\hline 0010033: Response to organic substance & 19 & $9.65 \times 10^{-4}$ & $\begin{array}{l}\text { F12, EIF2C2, AQP9, ALDOC, TAF9B, DUOX1, HSPA1A, } \\
\text { UBE2B, SDC1, HSF1, ADM, SLC25A36, ENO2, HSPA6, } \\
\text { HSPB1, SERPINA1, CA2, ABCC5, SPP1 }\end{array}$ \\
\hline 0000279: M phase & 12 & 0.00104 & $\begin{array}{l}\text { KIF 2C, CDCA8, PKMYT1, CHEK1, CDC20, PTTG1, } \\
\text { STMN1, CIT, RAD52, RCC1,RAD54L, FANCA }\end{array}$ \\
\hline 0006260: DNA replication & 8 & 0.00508 & $\begin{array}{l}\text { RFC4, POLD1, CDKN2D, CHTF 18, CHEK1, C16ORF75, } \\
\text { TK1, CDT1 }\end{array}$ \\
\hline 0007049: Cell cycle & 18 & 0.00517 & $\begin{array}{l}\text { CKS1B, PSRC1, PKMYT1, CHEK1, CDC20, PTTG1, } \\
\text { RAD52, RCC1, RAD54L, CDT1, KIF2C,CDCA8, POLD1, } \\
\text { CDKN2D, CHTF 18,STMN1, CIT, FANCA }\end{array}$ \\
\hline 0042060: Wound healing & 8 & 0.00522 & $\begin{array}{l}\text { F12, FGG, SDC1, MST1, ENO3, SERPINA1, SCNN1B, } \\
\text { TM4SF4 }\end{array}$ \\
\hline 0010035: Response to inorganic substance & 8 & 0.00761 & FGG, SDC1, AQP9, DUOX1, SERPINA1, CA2, ADA, MT3 \\
\hline 0000278: Mitotic cell cycle & 11 & 0.00785 & $\begin{array}{l}\text { KIF 2C, CDCA8, POLD1, CDKN2D, PKMYT1, CHEK1, } \\
\text { CDC20,PTTG1, STMN1, CIT, RCC1 }\end{array}$ \\
\hline
\end{tabular}

GO, Gene Ontology.

subunit- $\beta, C D C 20$ and $C D C 16$ were enriched in 'oocyte meiosis' $\left(\mathrm{P}=3.88 \times 10^{-5}\right)$; genes including ANAPC4, CDC20 and CDC16 were enriched in 'cell cycle' $(\mathrm{P}=0.003482)$ and 'ubiquitin mediated proteolysis' $(\mathrm{P}=0.004173$; Table VI).

The enriched GO analysis results revealed that the enriched GO functions for genes in module A were predominantly enriched in 'immune response' $\left(\mathrm{P}=6.77 \times 10^{-10}\right)$, 'taxis' $\left(\mathrm{P}=3.07 \times 10^{-5}\right)$ and 'chemotaxis' $\left(\mathrm{P}=3.07 \times 10^{-5}\right)$. The enriched GO functions for genes in module $\mathrm{B}$ were mainly enriched in 'mitotic cell cycle' $\left(\mathrm{P}=1.08 \times 10^{-11}\right)$, 'cell cycle phase' $\left(\mathrm{P}=2.39 \times 10^{-11}\right)$ and 'mitosis' $\left(\mathrm{P}=1.19 \times 10^{-10}\right.$; Table VII). 
Table IV. Top ten enriched GO functions of downregulated differentially expressed genes.

\begin{tabular}{|c|c|c|c|}
\hline GO term & Count & P-value & Genes \\
\hline 0010033: Response to organic substance & 28 & $3.50 \times 10^{-5}$ & $\begin{array}{l}\text { CCL2, SNCA, ADH5, PDE3B, PTEN, ASAH1, STAT6, } \\
\text { SORBS1, BCL2, PPP3CB, SRD5A2, GNG4, EIF } 2 B 4, \\
\text { GHR, KCNMA1, BSG, SLC8A1, SP100, SOCS } 2, F B P 1, \\
\text { LIFR, COLEC 12, SELS, CYP7B1, CD 38, PLA2G4A, } \\
\text { SMPD1, WFDC1 }\end{array}$ \\
\hline 0034097: Response to cytokine stimulus & 8 & $2.70 \times 10^{-4}$ & STAT6, CD38, SP100, BCL2, SNCA, LIFR, PPP3CB, GHR \\
\hline 0001666: Response to hypoxia & 10 & $3.07 \times 10^{-4}$ & $\begin{array}{l}\text { KCNMA1, CD 38, SLC8A1, SMAD9, CCL2, BCL2, PSEN2, } \\
C A B C 1, D P P 4, I T P R 2\end{array}$ \\
\hline 0009266: Response to temperature stimulus & 8 & $3.67 \times 10^{-4}$ & $\begin{array}{l}\text { PLA2G4A, CCL2, TRPM8, DIO2, BCL2, CIRBP, GMPR, } \\
\text { EIF } 2 B 4\end{array}$ \\
\hline 0070482 Response to oxygen levels & 10 & $4.47 \times 10^{-4}$ & $\begin{array}{l}\text { KCNMA1, CD38, SLC8A1, SMAD9, CCL2, BCL2, PSEN2, } \\
\text { CABC1, DPP4, ITPR2 }\end{array}$ \\
\hline 0007610 Behavior & 19 & $5.65 \times 10^{-4}$ & $\begin{array}{l}\text { KCNMA1, CCL2, SNCA, CXCL9, ATP1A2, FOSB, } \\
\text { CXCL11, PTEN, CXCL12, SLIT2, PTGDS, CCR5, BCL2, } \\
\text { PSEN2, GRPR, PTN, PBX3, FGF2, IL1RAPL1 }\end{array}$ \\
\hline 0006955 Immune response & 24 & $7.18 \times 10^{-4}$ & $\begin{array}{l}\text { GBP5, SP100, CCL2, GZMA, IGJ, SNCA, TUBB2C, } \\
\text { GPR65, CXCL9, COLEC12, CXCL11, CXCL12, } \\
\text { CLEC10A, IGSF6, CCR5, BCL2, PSEN2, MS4A2, } \\
\text { HLA-DRB5, HLA-DPB1, SPON2, IL1RAPL1, ERCC1, } \\
\text { RAB27A }\end{array}$ \\
\hline 0009725 Response to hormone stimulus & 16 & $8.63 \times 10^{-4}$ & $\begin{array}{l}\text { KCNMA1, BSG, CCL2, SOCS2, FBP1, PDE3B, PTEN, } \\
\text { CD38, PLA2G4A, SORBS1, BCL2,WFDC1, SRD5A2, } \\
\text { GNG4, EIF2B4, GHR }\end{array}$ \\
\hline 0042110 T-cell activation & 9 & $9.58 \times 10^{-4}$ & $\begin{array}{l}B C L 2, L C K, P S E N 2, P P P 3 C B, C D 2, C X C L 12, D P P 4, \\
R A B 27 A, R H O H\end{array}$ \\
\hline 0048511 Rhythmic process & 9 & 0.00106 & $\begin{array}{l}\text { KCNMA1, CYP7B1, HLF, PLA2G4A, EGR3, PTGDS, } \\
\text { BCL2, LFNG, EIF } 2 B 4\end{array}$ \\
\hline
\end{tabular}

GO, Gene Ontology.

\section{Discussion}

PCa is a relatively common cancer in men, with a subset ultimately developing metastatic disease to other regions of the body (25). The severity of the disease and its clinical heterogeneity, combined with the lack of effective diagnostic markers and therapeutic strategies, make the treatment of PCa a major challenge $(26,27)$. Therefore, it is urgent to screen key genes that are associated with the metastasis of PCa with the aim of improving its treatment. The present study used bioinformatics methods to identify the DEGs between metastatic and localized PCa expression profiles. The results revealed that the expression of 561 genes (including 208 upregulated and 353 downregulated genes) was altered in metastatic $\mathrm{PCa}$, compared with localized PCa. PPI networks were then constructed to reveal the associations among these genes. Furthermore, two potentially important modules were selected from the downregulated DEG set and their functions were determined by GO and KEGG pathway analyses.

The upregulated DEGs were significantly enriched in 'response to hypoxia' and 'response to oxygen levels'. Hypoxia increases the likelihood of tumor invasion and metastasis by activating relevant gene expression through the expression of hypoxia-inducible factor (HIF) (28). HIF is a transcription factor that responds to changes in the available oxygen in the cell (29). A previous study demonstrated that hypoxia may regulate each step in the process of tumor metastasis, from the initial epithelial-mesenchymal transition to the final organotropic colonization (28). Hypoxia also increases the mRNA expression of lysyl oxidase, which is associated with the early and later stages of metastasis (30). It also has been reported that hypoxia promotes cell invasion in PCa cells (31). Thus, these genes may be associated with the metastasis of PCa.

In addition, it was identified that the downregulated DEGs were enriched in 'calcium signaling pathway'. Calcium, as a ubiquitous second messenger, is an important signaling molecule that is involved in numerous fundamental physiological functions, including the cell cycle, apoptosis and migration (32). Certain human diseases have been associated with the dysregulation of calcium homeostasis, including hypertension, diabetes, Alzheimer's disease, cardiovascular disease and cancer $(33,34)$. Calcium signaling in cancer cells has been demonstrated to be associated with events during tumor progression, including migration, invasion and 


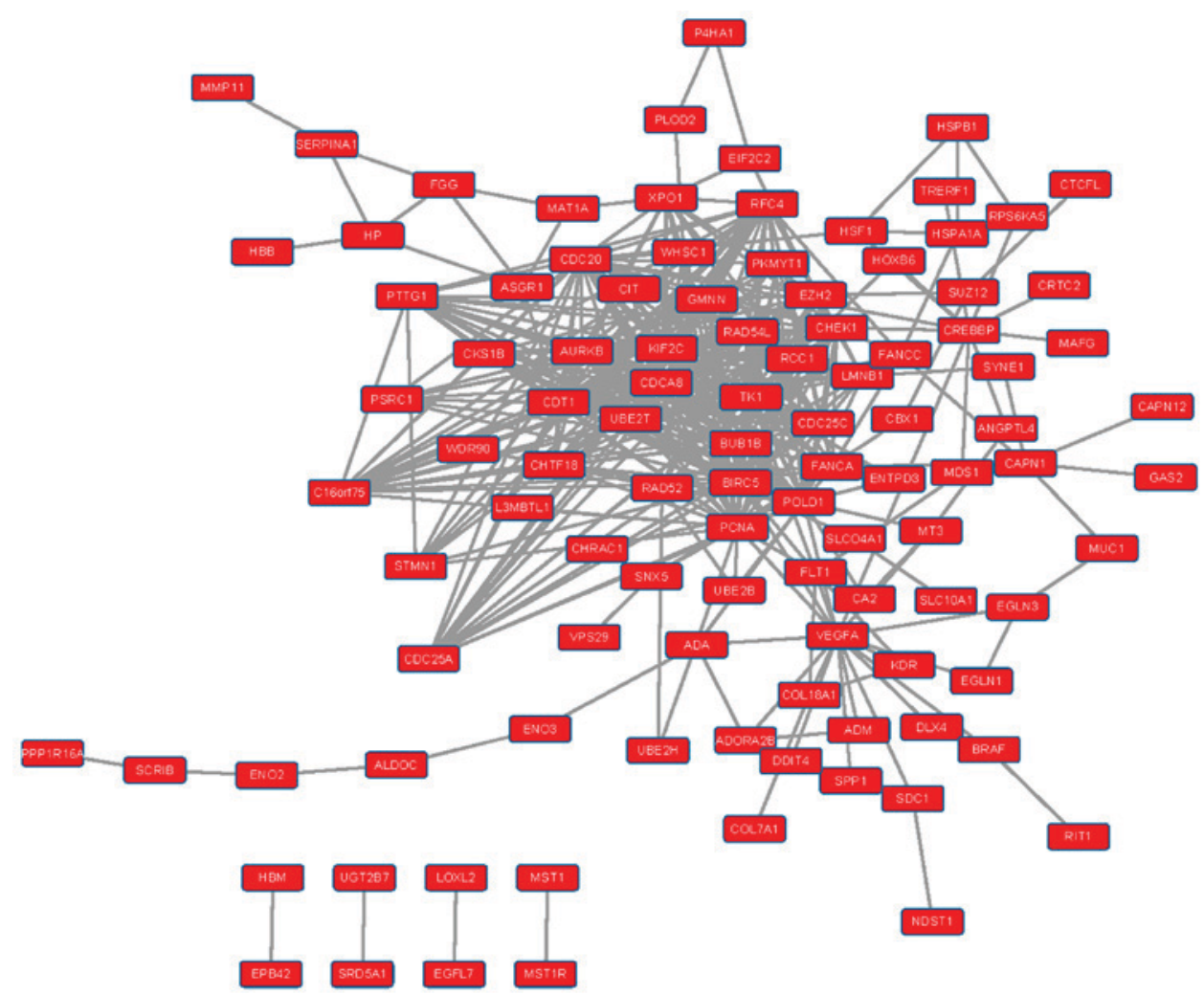

Figure 1. Protein-protein interaction network of the upregulated differentially expressed genes between metastatic and localized prostate cancer tissue samples.

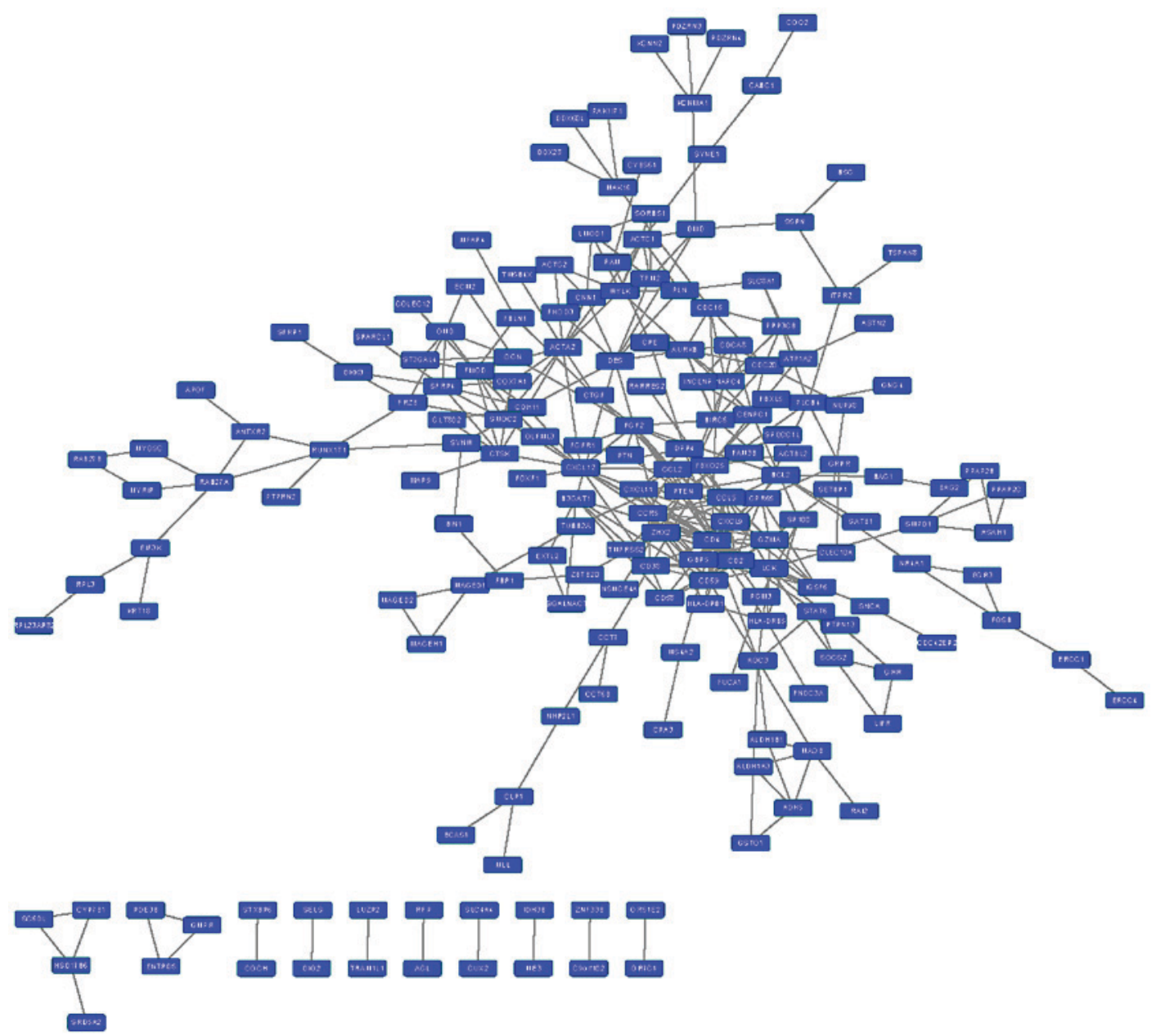

Figure 2. Protein-protein interaction network for downregulated differentially expressed genes between metastatic and localized prostate cancer tissue samples. 
Table V. Differentially expressed genes with the top-20 highest connectivity degree in the protein-protein interaction network.

\begin{tabular}{|c|c|c|}
\hline Status & Gene symbol & Degree \\
\hline \multirow[t]{20}{*}{ Upregulated } & PCNA & 34 \\
\hline & CDCA8 & 30 \\
\hline & $C D C 20$ & 30 \\
\hline & BIRC5 & 30 \\
\hline & POLDI & 29 \\
\hline & $C D T 1$ & 29 \\
\hline & $K I F 2 C$ & 28 \\
\hline & CHEKI & 28 \\
\hline & $A U R K B$ & 28 \\
\hline & $T K 1$ & 27 \\
\hline & RFC4 & 27 \\
\hline & $B U B 1 B$ & 27 \\
\hline & $R A D 54 L$ & 25 \\
\hline & $U B E 2 T$ & 22 \\
\hline & $C D C 25 C$ & 21 \\
\hline & $G M N N$ & 20 \\
\hline & C16orf75 & 19 \\
\hline & PTTG1 & 19 \\
\hline & $E Z H 2$ & 18 \\
\hline & $C D C 25 A$ & 18 \\
\hline \multirow[t]{20}{*}{ Downregulated } & CD4 & 25 \\
\hline & CCR5 & 15 \\
\hline & $L C K$ & 15 \\
\hline & CXCL12 & 14 \\
\hline & $F M O D$ & 13 \\
\hline & $F G F 2$ & 13 \\
\hline & CXCL9 & 12 \\
\hline & $C D 2$ & 12 \\
\hline & CD69 & 12 \\
\hline & CCL5 & 12 \\
\hline & PTEN & 11 \\
\hline & ACTA2 & 11 \\
\hline & GZMA & 11 \\
\hline & BIRC5 & 10 \\
\hline & $C C L 2$ & 9 \\
\hline & $D E S$ & 9 \\
\hline & $C D C 20$ & 9 \\
\hline & $A U R K B$ & 9 \\
\hline & SFRP4 & 9 \\
\hline & $M Y L K$ & 9 \\
\hline
\end{tabular}

metastasis (35). Several membrane-bound $\mathrm{Ca}^{2+}$ channels have been reported to have critical roles in regulating cancer cell migration and malignant metastasis $(32,36)$. Cationic channels of the transient receptor potential (TRP) family are considered to be key players in calcium homoeostasis (37). The expression of transient receptor potential melastain 8 (TRPM8), part of the TRP channel subfamily, has been demonstrated to reduce the migration of PCa PC-3 cells $(37,38)$. TRP vanilloid 2 , another TRP channel, enhances PCa cell migration and
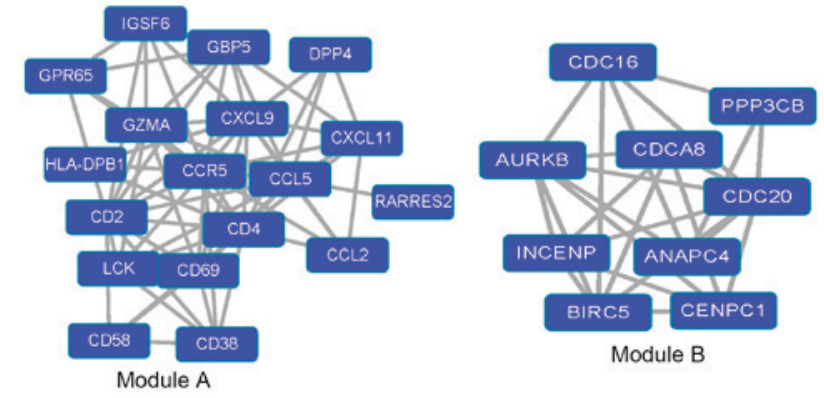

Figure 3. Module A and module B of the protein-protein interaction network for downregulated differentially expressed genes between metastatic and localized prostate cancer tissue samples.

invasion (39). Therefore, the DEGs enriched in 'response to hypoxia' and 'calcium signaling pathway' may contribute to the metastasis of $\mathrm{PCa}$.

Based on the result of a PPI network construction from the DEGs, it was identified that a number of DEGs may be linked with others. $C D 4, L C K$ and CCR5 had high degrees of connectivity in the PPI network and were associated with 'immune system'. It has been reported that a range of T-cell subsets found in solid tumors are associated with tumor progression and metastasis (40). CD4 encodes a T-lymphocyte membrane glycoprotein and functions as an adhesion molecule that binds to non-polymorphic regions of major histocompatibility complex class II antigens $(41,42)$. CD $4^{+}$ cells are involved in the pulmonary metastasis of mammary carcinoma (43). It has been reported that the infiltrating $\mathrm{CD} 4^{+}$ $\mathrm{T}$ cells may promote PCa metastasis (44). Furthermore, $C D 4$ was also associated with 'cell adhesion molecules (CAMs)' in module A. CAMs, which belong to the family of membrane receptors that mediate cell-matrix and cell-cell interactions, are essential for transducing intracellular signals, which are responsible for facilitating cell adhesion, invasion, migration and metastasis (45). $L C K$ is a member of the Src tyrosine kinase family expressed primarily in $\mathrm{T}$ lymphocytes and natural killer cells (46). LCK localizes to the surface of the plasma membrane and binds to transmembrane receptors, including CD4 (47). CCR5, a protein on the surface of white blood cells, has been demonstrated to alter the proliferation of PCa cells (47). In the present study, $L C K$ and CCR 5 were connected to $C D 4$ in the PPI network. Therefore, we hypothesize that $C D 4, L C K$ and $C C R 5$ could have important roles in the metastasis of $\mathrm{PCa}$.

PCNA exhibited a high degree of connectivity in the PPI network for upregulated DEGs. PCNA belongs to the family of DNA sliding clamps, is essential for DNA replication and is associated with DNA repair, chromatin remodeling and epigenetics (48). The phosphorylation of PCNA is a frequent event in the development of prostate cancer (49). It was demonstrated that PCNA was highly expressed in triple-negative breast cancer and associated with axillary lymph node metastasis (50). Although the regulation of PCNA function in prostate cancer cells has not been fully characterized, the data of the present study indicated that PCNA may have a critical role in PCa metastasis.

GO analysis of module B revealed that the DEGs were enriched in terms associated with the cell cycle. 
Table VI. Enriched Kyoto Encyclopedia of Genes and Genomes pathways for genes in module A and module B.

\begin{tabular}{|c|c|c|c|c|}
\hline Module & Term & Count & P-value & Genes \\
\hline \multirow[t]{5}{*}{ A } & hsa04062: Chemokine signaling pathway & 5 & $4.77 \times 10^{-4}$ & CCL2, CCR5, CXCL9, CXCL11, CCL5 \\
\hline & hsa04060: Cytokine-cytokine receptor interaction & 5 & 0.00171 & CCL2, CCR5, CXCL9, CXCL11, CCL5 \\
\hline & hsa04514: Cell adhesion molecules & 4 & 0.00242 & $C D 58, C D 2, C D 4, H L A-D P B 1$ \\
\hline & hsa04640: Hematopoietic cell lineage & 3 & 0.01408 & $C D 38, C D 2, C D 4$ \\
\hline & hsa04620: Toll-like receptor signaling pathway & 3 & 0.01912 & CXCL9, CXCL11, CCL5 \\
\hline \multirow[t]{3}{*}{ B } & hsa04114: Oocyte meiosis & 4 & $3.88 \times 10^{-5}$ & ANAPC4, PPP3CB, CDC20, CDC16 \\
\hline & hsa04110: Cell cycle & 3 & 0.003482 & ANAPC4, CDC20, CDC16 \\
\hline & hsa04120: Ubiquitin mediated proteolysis & 3 & 0.004173 & $A N A P C 4, C D C 20, C D C 16$ \\
\hline
\end{tabular}

Table VII. Top ten enriched GO functions for genes in module A and module B.

\begin{tabular}{|c|c|c|c|c|}
\hline Module & GO term & Count & P-value & Genes \\
\hline \multirow[t]{10}{*}{ A } & $\begin{array}{l}0006955 \text { Immune } \\
\text { response }\end{array}$ & 11 & $6.77 \times 10^{-10}$ & $\begin{array}{l}\text { IGSF6, GBP5, CCL2, CCR5, GZMA, GPR65, CXCL9, } \\
\text { CD4, HLA-DPB1, CXCL11, CCL5 }\end{array}$ \\
\hline & 0042330 Taxis & 5 & $3.07 \times 10^{-5}$ & CCL2, CCR5, CXCL9, CXCL11, CCL5 \\
\hline & 0006935 Chemotaxis & 5 & $3.07 \times 10^{-5}$ & CCL2, CCR5, CXCL9, CXCL11, CCL5 \\
\hline & $\begin{array}{l}0006874 \text { Cellular calcium } \\
\text { ion homeostasis }\end{array}$ & 5 & $5.19 \times 10^{-5}$ & CD38, CCL2, CCR5, LCK, CCL5 \\
\hline & $\begin{array}{l}0055074 \text { Calcium ion } \\
\text { homeostasis }\end{array}$ & 5 & $5.77 \times 10^{-5}$ & CD38, CCL2, CCR5, LCK, CCL5 \\
\hline & $\begin{array}{l}0006875 \text { Cellular metal ion } \\
\text { homeostasis }\end{array}$ & 5 & $6.79 \times 10^{-5}$ & CD38, CCL2, CCR5, LCK, CCL5 \\
\hline & $\begin{array}{l}0007166 \text { Cell surface receptor } \\
\text { linked signal transduction }\end{array}$ & 10 & $7.77 \times 10^{-5}$ & $\begin{array}{l}\text { IGSF6, CCL2, CCR5, LCK, GPR65, CD2, CXCL9, } \\
\text { CD4, CXCL11, CCL5 }\end{array}$ \\
\hline & 0055065 Metal ion homeostasis & 5 & $8.08 \times 10^{-5}$ & CD38, CCL2, CCR5, LCK, CCL5 \\
\hline & $\begin{array}{l}0030005 \text { Cellular di-, tri-valent } \\
\text { inorganic Cation homeostasis }\end{array}$ & 5 & $1.20 \times 10^{-4}$ & CD38, CCL2, CCR5, LCK, CCL5 \\
\hline & $\begin{array}{l}0055066 \mathrm{Di}-, \text { tri-valent inorganic } \\
\text { cation homeostasis }\end{array}$ & 5 & $1.46 \times 10^{-4}$ & CD38, CCL2, CCR5, LCK, CCL5 \\
\hline \multirow[t]{10}{*}{$\mathrm{B}$} & 0000278 Mitotic cell cycle & 8 & $1.08 \times 10^{-11}$ & $\begin{array}{l}\text { CDCA8, INCENP, ANAPC4, PPP } 3 C B, B I R C 5, C D C 20, \\
C D C 16, A U R K B\end{array}$ \\
\hline & 0022403 Cell cycle phase & 8 & $2.39 \times 10^{-11}$ & $\begin{array}{l}\text { CDCA8, INCENP, ANAPC4, PPP3CB, BIRC5, CDC20, } \\
C D C 16, A U R K B\end{array}$ \\
\hline & 0007067 Mitosis & 7 & $1.19 \times 10^{-10}$ & $\begin{array}{l}\text { CDCA8, INCENP, ANAPC4, BIRC5, CDC } 20, C D C 16, \\
A U R K B\end{array}$ \\
\hline & 0000280 Nuclear division & 7 & $1.19 \times 10^{-10}$ & $\begin{array}{l}\text { CDCA8, INCENP, ANAPC4, BIRC5, CDC } 20, \text { CDC } 16, \\
A U R K B\end{array}$ \\
\hline & $\begin{array}{l}0000087 \mathrm{M} \text { phase of mitotic } \\
\text { cell cycle }\end{array}$ & 7 & $1.33 \times 10^{-10}$ & $\begin{array}{l}\text { CDCA8, INCENP, ANAPC4, BIRC5, CDC20, CDC16, } \\
A U R K B\end{array}$ \\
\hline & 0048285 Organelle fission & 7 & $1.52 \times 10^{-10}$ & $\begin{array}{l}\text { CDCA8, INCENP, ANAPC4, BIRC5, CDC } 20, C D C 16, \\
A U R K B\end{array}$ \\
\hline & 0022402 Cell cycle process & 8 & $2.14 \times 10^{-10}$ & $\begin{array}{l}\text { CDCA8, INCENP, ANAPC4, PPP } 3 C B, B I R C 5, C D C 20, \\
C D C 16, A U R K B\end{array}$ \\
\hline & 0051301 Cell division & 7 & $7.03 \times 10^{-10}$ & $\begin{array}{l}\text { CDCA8, INCENP, ANAPC4, BIRC5, CDC20, CDC16, } \\
A U R K B\end{array}$ \\
\hline & 0000279 M-phase & 7 & $1.36 \times 10^{-9}$ & $\begin{array}{l}\text { CDCA8, INCENP, ANAPC4, BIRC5, CDC } 20, \text { CDC16, } \\
A U R K B\end{array}$ \\
\hline & 0007049 Cell cycle & 8 & $1.99 \times 10^{-9}$ & $\begin{array}{l}\text { CDCA8, INCENP, ANAPC4, PPP3CB, BIRC5, CDC20, } \\
C D C 16, A U R K B\end{array}$ \\
\hline
\end{tabular}


For example, BIRC5, CDCA8, inner centromere protein, $A N A P C 4, C D C 20, C D C 16$ and $A U R K B$ were enriched in 'mitosis', 'nuclear division', 'M phase of mitotic cell cycle' and 'organelle fission'. Cell cycle deregulation is a common feature of tumors (51). BIRC5 is a member of the inhibitor of apoptosis protein family, which has a critical role in the occurrence and progression of tumors (52). BIRC5 has been reported to be associated with colorectal cancer tumorigenesis and progress (53). BIRC5, as a component of the chromosomal passenger complex, is involved in the microtubule-kinetochore attachment that ensures cohesion between sister chromatids and centrosome aggregation (54). The regulation of centrosome coalescence may link mitosis to cell adhesion (55). Therefore, BIRC5 may be associated with PCa cell metastasis.

There are certain limitations to the present study; due to the in silico nature of the analysis of the PCa expression profiles, the obtained results were only forecasted with contrived criteria. Therefore, a number of important genes may have been ignored. The absence of experiments verifying the expression of DEGs was also a limitation in the present study. The limited sample size may also represent a limitation and restrict the ability to draw a valid conclusion. Despite these caveats, the results identified in the present study may provide a novel stimulus for the further experimental study of PCa metastasis.

The present study analyzed the gene expression profiles of localized and metastatic PCa tissue using bioinformatics analysis. It was identified that DEGs, including CD4, PCNA and $B I R 5 C$, may serve roles in driving the metastasis of PCa. These genes may be novel potential biomarkers and/or therapeutic targets for patients with PCa. However, further research is required to confirm these results.

\section{Acknowledgements}

The present study was supported by a grant from the Scientific Research program of Jilin provincial Health department (grant no. 3D5157343428).

\section{References}

1. Djulbegovic M, Beyth RJ, Neuberger MM, Stoffs TL, Vieweg J, Djulbegovic B and Dahm P: Screening for prostate cancer: Systematic review and meta-analysis of randomised controlled trials. Bmj 341: c4543, 2010.

2. Henry RY and O'Mahony D: Treatment of prostate cancer. J Clin Pharm Ther 24: 93-102, 1999.

3. Siegel R, Naishadham D and Jemal A: Cancer statistics, 2012. CA Cancer J Clin 62: 10-29, 2012.

4. Lozano R, Naghavi M, Foreman K, Lim S, Shibuya K, Aboyans V, Abraham J, Adair T, Aggarwal R, Ahn SY, et al: Global and regional mortality from 235 causes of death for 20 age groups in 1990 and 2010: A systematic analysis for the global burden of disease study 2010. Lancet 380: 2095-2128, 2012.

5. Abate-Shen C and Shen MM: Molecular genetics of prostate cancer. Genes Dev 14: 2410-2434, 2000.

6. Hafeez BB, Zhong W, Fischer JW, Mustafa A, Shi X, Meske L, Hong H, Cai W, Havighurst T, Kim K and Verma AK: Plumbagin, a medicinal plant (Plumbago zeylanica)-derived 1,4-naphthoquinone, inhibits growth and metastasis of human prostate cancer PC-3M-luciferase cells in an orthotopic xenograft mouse model. Mol Oncol 7: 428-439, 2013.

7. Pani G, Galeotti T and Chiarugi P: Metastasis: Cancer cell's escape from oxidative stress. Cancer Metastasis Rev 29: 351-378, 2010 .
8. Spano D, Heck C, De Antonellis P, Christofori G and Zollo M: Molecular networks that regulate cancer metastasis. Semin Cancer Biol 22: 234-249, 2012.

9. Coso S and Williams ED: Prostate Cancer Lymph Node Metastasis. 2009.

10. Woollard DJ, Opeskin K, Coso S, Wu D, Baldwin ME and Williams ED: Differential expression of VEGF ligands and receptors in prostate cancer. Prostate 73: 563-572, 2013.

11. Zhou H, Kuang J, Zhong L, Kuo WL, Gray JW, Sahin A, Brinkley BR and Sen S: Tumour amplified kinase STK15/BTAK induces centrosome amplification, aneuploidy and transformation. Nat Genet 20: 189-193, 1998.

12. Grubb RL, Deng J, Pinto PA, Mohler JL, Chinnaiyan A, Rubin M, Linehan WM, Liotta LA, Petricoin EF and Wulfkuhle JD: Pathway biomarker profiling of localized and metastatic human prostate cancer reveal metastatic and prognostic signatures. J Proteome Res 8: 3044-3054, 2009.

13. Watahiki A, Wang Y, Morris J, Dennis K, O'Dwyer HM, Gleave M, Gout PW and Wang Y: MicroRNAs associated with metastatic prostate cancer. PLOS One 6: e24950, 2011.

14. Prensner JR, Rubin MA, Wei JT and Chinnaiyan AM: Beyond PSA: The next generation of prostate cancer biomarkers. Sci Transl Med 4: 127rv3, 2012.

15. Kim JH, Dhanasekaran SM, Prensner JR, Cao X, Robinson D, Kalyana-Sundaram S, Huang C, Shankar S, Jing X, Iyer M, et al: Deep sequencing reveals distinct patterns of DNA methylation in prostate cancer. Genome Res 21: 1028-1041, 2011.

16. Irizarry RA, Hobbs B, Collin F, Beazer-Barclay YD, Antonellis KJ, Scherf U and Speed TP: Exploration, normalization, and summaries of high density oligonucleotide array probe level data. Biostatistics 4: 249-264, 2003.

17. Lopez-Romero P: AgiMicroRna: Processing and Differential Expression Analysis of Agilent microRNA chips. R package version $2.24 .0,2016$

18. Smyth GK: Linear models and empirical bayes methods for assessing differential expression in microarray experiments. Stat Appl Genet Mol Biol 3, 2004.

19. Benjamini $Y$ and Hochberg Y: Controlling the false discovery rate: A practical and powerful approach to multiple testing. J Royal Stat Society Series B (Methodological) 57: 289-300, 1995.

20. Huang DW, Sherman BT, Tan Q, Kir J, Liu D, Bryant D, Guo Y, Stephens R, Baseler MW, Lane HC and Lempicki RA: DAVID bioinformatics resources: Expanded annotation database and novel algorithms to better extract biology from large gene lists. Nucleic Acids Res 35: W169-W175, 2007.

21. Keshava Prasad TS, Goel R, Kandasamy K, Keerthikumar S, Kumar S, Mathivanan S, Telikicherla D, Raju R, Shafreen B, Venugopal A, et al: Human protein reference database-2009 update. Nucleic Acids Res 37 (Database issue): D767-D772, 2009.

22. Chatr-aryamontri A, Breitkreutz BJ, Heinicke S, Boucher L, Winter A, Stark C, Nixon J, Ramage L, Kolas N, O'Donnell L, et al: The BioGRID interaction database: 2013 update. Nucleic Acids Res 41 (Database issue): D816-D823, 2013.

23. Franceschini A, Szklarczyk D, Frankild S, Kuhn M, Simonovic M, Roth A, Lin J, Minguez P, Bork P, von Mering C and Jensen LJ: STRING v9.1: Protein-protein interaction networks, with increased coverage and integration. Nucleic Acids Res 41 (Database issue): D808-D815, 2013.

24. Shannon P, Markiel A, Ozier O, Baliga NS, Wang JT, Ramage D, Amin N, Schwikowski B and Ideker T: Cytoscape: A software environment for integrated models of biomolecular interaction networks. Genome Res 13: 2498-2504, 2003.

25. Lee KC, Bradley DA, Hussain M, Meyer CR, Chenevert TL, Jacobson JA, Johnson TD, Galban CJ, Rehemtulla A, Pienta KJ and Ross BD: A feasibility study evaluating the functional diffusion map as a predictive imaging biomarker for detection of treatment response in a patient with metastatic prostate cancer to the bone. Neoplasia 9: 1003-1011, 2007.

26. Perabo F, Von Löw E, Ellinger J, Von Rücker A, Müller S and Bastian P: Soy isoflavone genistein in prevention and treatment of prostate cancer. Prostate Cancer Prostatic Dis 11: 6-12, 2007.

27. Shen MM and Abate-Shen C: Molecular genetics of prostate cancer: New prospects for old challenges. Genes Dev 24: 1967-2000, 2010.

28. Lu X and Kang Y: Hypoxia and hypoxia-inducible factors: Master regulators of metastasis. Clin Cancer Res 16: 5928-5935, 2010.

29. Smith TG, Robbins PA and Ratcliffe PJ: The human side of hypoxia-inducible factor. Br J Haematol 141: 325-334, 2008.

30. Erler JT and Giaccia AJ: Lysyl oxidase mediates hypoxic control of metastasis. Cancer Res 66: 10238-10241, 2006. 
31. Bae K, Dai Y, Vieweg J and Siemann D: Hypoxia increases the expression of stem-cell markers and promotes cell invasion in prostate cancer cells. Cancer Res 71: 485, 2011.

32. Chen YF, Chen YT, Chiu WT and Shen MR: Remodeling of calcium signaling in tumor progression. J Biomed Sci 20: 23, 2013

33. Rizzuto R and Pozzan T: When calcium goes wrong: Genetic alterations of a ubiquitous signaling route. Nat Genet 34: 135-141, 2003.

34. Parekh AB: Store-operated CRAC channels: Function in health and disease. Nat Rev Drug Discov 9: 399-410, 2010.

35. Monteith GR, Davis FM and Roberts-Thomson SJ: Calcium channels and pumps in cancer: Changes and consequences. J Biol Chem 287: 31666-31673, 2012.

36. Prevarskaya N, Skryma R and Shuba Y: Calcium in tumour metastasis: New roles for known actors. Nat Rev Cancer 11: 609-618, 2011.

37. Yang ZH, Wang XH, Wang HP and Hu LQ: Effects of TRPM8 on the proliferation and motility of prostate cancer PC-3 cells. Asian J Androl 11: 157-165, 2009.

38. Gkika D, Flourakis M, Lemonnier L and Prevarskaya N: PSA reduces prostate cancer cell motility by stimulating TRPM8 activity and plasma membrane expression. Oncogene 29: 4611-4616, 2010

39. Monet M, Lehen'kyi V, Gackiere F, Firlej V, Vandenberghe M, Roudbaraki M, Gkika D, Pourtier A, Bidaux G, Slomianny C, et al: Role of cationic channel TRPV2 in promoting prostate cancer migration and progression to androgen resistance. Cancer Res 70: 1225-1235, 2010.

40. Grivennikov SI, Greten FR and Karin M: Immunity, inflammation, and cancer. Cell 140: 883-899, 2010

41. Littman DR: The structure of the CD4 and CD8 genes. Annu Rev Immunol 5: 561-584, 1987.

42. Foti M,Phelouzat MA,Holm A, Rasmusson BJ and Carpentier JL: p56Lck anchors CD4 to distinct microdomains on microvilli Proc Natl Acad Sci USA 99: 2008-2013, 2002.

43. DeNardo DG, Barreto JB, Andreu P, Vasquez L, Tawfik D, Kolhatkar N and Coussens LM: CD4(+) T cells regulate pulmonary metastasis of mammary carcinomas by enhancing protumor properties of macrophages. Cancer Cell 16: 91-102, 2009.
44. Hu S, Li L, Yeh S, Cui Y, Li X, Chang HC, Jin J and Chang C: Infiltrating $\mathrm{T}$ cells promote prostate cancer metastasis via modulation of FGF11->miRNA-541->androgen receptor (AR)->MMP9 signaling. Mol Oncol 9: 44-57, 2015.

45. Li DM and Feng YM: Signaling mechanism of cell adhesion molecules in breast cancer metastasis: Potential therapeutic targets. Breast Cancer Res Trea 128: 7-21, 2011.

46. Hawash IY, Hu XE, Adal A, Cassady JM, Geahlen RL and Harrison ML: The oxygen-substituted palmitic acid analogue, 13-oxypalmitic acid, inhibits Lck localization to lipid rafts and T cell signaling. Biochim Biophys Acta 1589: 140-150, 2002.

47. Vaday GG, Peehl DM, Kadam PA and Lawrence DM: Expression of CCL5 (RANTES) and CCR5 in prostate cancer. Prostate 66: 124-134, 2006

48. Moldovan GL, Pfander B and Jentsch S: PCNA, the maestro of the replication fork. Cell 129: 665-679, 2007.

49. Zhao H, Lo YH, Ma L, Waltz SE, Gray JK, Hung MC and Wang SC: Targeting tyrosine phosphorylation of PCNA inhibits prostate cancer growth. Mol Cancer Ther 10: 29-36, 2011.

50. Jiaping P: Abstract B104: Expressions of PCNA in triple negative breast cancers and Their clinical significance. Cancer Prev Res 5: B104, 2012.

51. Malumbres M and Barbacid M: Cell cycle, CDKs and cancer: A changing paradigm. Nat Rev Cancer 9: 153-166, 2009.

52. Altieri DC: Survivin, cancer networks and pathway-directed drug discovery. Nat Rev Cancer 8: 61-70, 2008.

53. Wang H, Zhang X, Wang L, Zheng G, Du L, Yang Y, Dong Z, Liu Y, Qu A and Wang C: Investigation of cell free BIRC5 mRNA as a serum diagnostic and prognostic biomarker for colorectal cancer. J Surg Oncol 109: 574-579, 2014.

54. Vitale I, Galluzzi L, Senovilla L, Criollo A, Jemaà M, Castedo M and Kroemer G: Illicit survival of cancer cells during polyploidization and depolyploidization. Cell Death Differ 18: 1403-1413, 2010.

55. Kwon M, Godinho SA, Chandhok NS, Ganem NJ, Azioune A, Thery $\mathrm{M}$ and Pellman D: Mechanisms to suppress multipolar divisions in cancer cells with extra centrosomes. Genes Dev 22: 2189-2203, 2008. 